\title{
Estudo da forma arquitetônica \\ do Santuário Nossa \\ Senhora do Perpétuo \\ Socorro - Salgueiro/PE
}

\author{
Maria Izabel Rego Cabral, \\ Antônio Italcy de Oliveira Junior, \\ Yanne Pereira de Andrade Santos*
}

\begin{abstract}
Resumo O objetivo desta pesquisa é analisar a forma arquitetônica do Santuário Nossa Senhora do Perpétuo Socorro, enquanto tipo funcional religioso que possui referências modernistas. A construção, localizada em Salgueiro, Pernambuco, foi idealizada por um pároco da época e construída por um morador da comunidade local em 1985, sendo reformada na década de 1990 resultando na sua forma atual. Foram realizadas visitas de campo onde ocorreram levantamentos métricos, registros fotográficos, diálogos públicos com o pároco responsável atualmente e com pessoas da comunidade que foram diretamente envolvidas com a construção do santuário. A construção executada sem projeto arquitetônico é aqui considerada como autoconstrução. A expressão plástica de repetição de estruturas dispostas radialmente da mesma aproxima-se formalmente de relevantes templos sacros modernistas brasileiros.
\end{abstract}

Palavras-chave: arquitetura de espaços sagrados, forma arquitetônica, modernismo brasileiro.

\section{Estudio de la forma arquitectónica del Santuario de Nossa Senhora do Perpétuo Socorro - Salgueiro / PE}

Resumen El objetivo de esta investigación es analizar la forma arquitectónica del Santuario Nossa Senhora do Perpétuo Socorro, como un tipo religioso funcional que tiene referencias modernistas. El edificio, ubicado en Salgueiro, Pernambuco, fue diseñado por un párroco y construido por un residente de la comunidad local en 1985, y fue renovado en la década de 1990, dando como resultado su forma actual. Se realizaron visitas de campo para métricas, registros fotográficos, diálogos públicos con el pastor actualmente responsable y con personas que estuvieron directamente involucradas en la construcción del santuario. La construcción realizada sin diseño arquitectónico se considera aquí como autoconstrucción. La expresión plástica de la repetición de estructuras dispuestas radialmente se acerca formalmente a templos sagrados modernistas brasileños relevantes.

Palabras clave: arquitectura de espacios sagrados, forma arquitectónica, modernismo brasileño.

\section{Study of the architectural form of the Nossa Senhora do Perpétuo Socorro Sanctuary - Salgueiro / PE}

Abstract The objective of this research is to analyze the architectural form of the Sanctuary Nossa Senhora do Perpétuo Socorro, while the functional religious type that presents modern references. The building, located in Salgueiro, Pernambuco, was designed by a priest and built by a resident of the local community in 1985, being renovated in the 1990s, resulting in its current form. Field visits were carried out where metric surveys, photographic records, public dialogues with the priest and with people from the community who were directly involved with the construction of building. This Santuary, carried out without architectural project, is considered here as self-construction. The plastic expression of repetition of structures disposed radially of it formally approaches relevant Brazilian modernist sacred temples.

Keywords: architecture of sacred spaces, architectural form, brazilian modernism. 
A paróquia do Santuário Nossa Senhora do Perpétuo Socorro (Figura 1) constitui um importante marco arquitetônico de Salgueiro ${ }^{1}$, cidade localizada na região do sertão central do estado de Pernambuco. Por esse motivo, a igreja foi escolhida como objeto de análise da pesquisa que deu origem a este artigo, realizada por professores e alunos do curso técnico em Edificações do Instituto Federal de Educação, Ciência e Tecnologia do Sertão Pernambucano (IFSPE), campus Salgueiro entre 2018 e 2019, que teve como objetivo a análise da forma arquitetônica desse santuário.

Este artigo é fruto da pesquisa desenvolvida durante 12 meses, entre Novembro de 2018 e Novembro de 2019, que teve caráter exploratório e interdisciplinar, e que envolveu etapas de estudo teórico envolvendo docentes e discentes. Nesses encontros, fundamentados por revisões bibliográficas, foram debatidos aspectos do projeto moderno e das expressões da modernidade nas construções públicas e privadas, seculares e sacras, que fundamentariam as posteriores observações e análises do Santuário.

A partir do segundo trimestre de pesquisa, o estudo de campo foi realizado. Este se desdobrou em levantamentos documentais da Paróquia e documentos de domínio público. Além disso, foram realizadas entrevistas semiestruturadas com sujeitos-chave, identificados por meio da análise documental. Estas entrevistas ajudaram a construir uma narrativa loco-regional sobre a construção do Santuário e da figura presente no discurso popular, o "Engenheiro dos Pobres".

A equipe também realizou levantamentos fotográficos e métricos do templo e da região em que este está situado, bem como o desenho arquitetônico da edificação. Os resultados da pesquisa foram apresentados à Paroquia e aos demais sujeitos do estudo, buscando contribuir com o registro e documentação sobre esta construção, simbolicamente valiosa para a população da região.

* Maria Izabel Rego Cabral possui Doutorado em Design pela Universidade Federal de Pernambuco, Instituto Federal do Sertão Pernambucano Campus Salgueiro, ORCID <https://orcid. org/0000-0002-0602-4033>. Antônio Italcy de Oliveira Junior é Doutorando em Engenharia Civil pela Universidade Federal de Pernambuco, Instituto Federal do Sertão Pernambucano Campus Salgueiro, ORCID <https://orcid. org/0000-0002-8297-5068>.

Yanne Pereira de Andrade Santos é Arquiteta e Urbanista, Professora do do Instituto Federal de Educação, Ciência e Tecnologia do Sertão Pernambucano - Campus Salgueiro, ORCID <https://orcid. org/0000-0001-5405-8804>.
A análise da forma arquitetônica ainda permitiu avaliar o grau de proximidade entre a arquitetura do Santuário e outras edificações sacras modernistas. Através de análise comparativa, a forma desta edificação foi relacionada a exemplares de templos sagrados modernos que também possuem planta central e estrutura radial em concreto armado. Desta forma, se configura como um dos questionamentos da pesquisa o alcance da arquitetura moderna na cultura material, a ponto de influenciar a forma de planejar as edificações, mesmo fora do meio profissional da Arquitetura e da Engenharia. Será que o fato de não ter sido projetada por um arquiteto ou engenheiro desqualifica a obra enquanto exemplo de arquitetura moderna?

Como produto do projeto, foram gerados os desenhos arquitetônicos do santuário e do campanário, o que era uma demanda do padre Remígio de Vettor, atual responsável pela paróquia, feita à equipe. Não foi possível a realização do levantamento topográfico, o que possibilitaria a representação das curvas de nível e correto desenho 


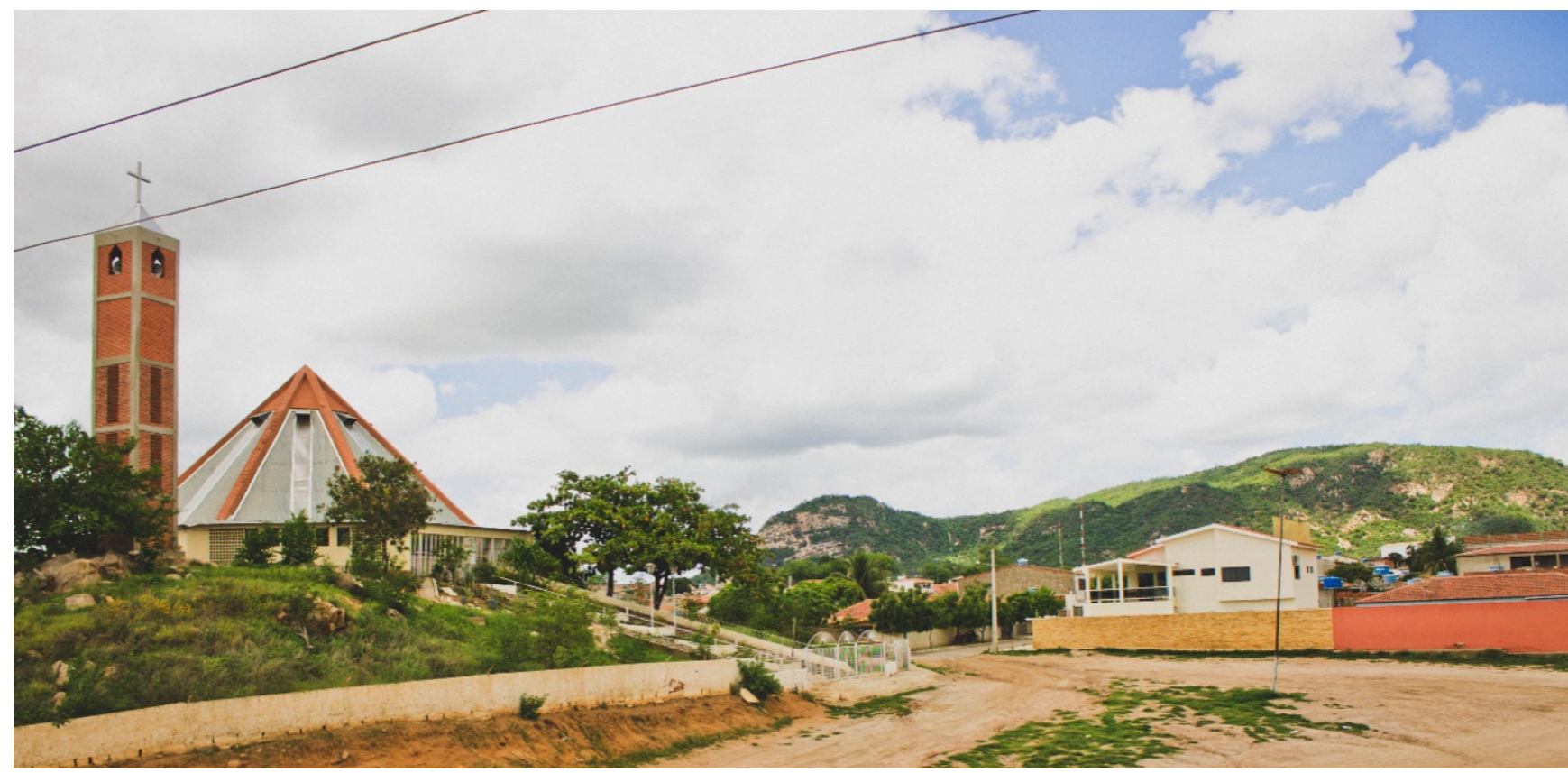

Figura 1: Santuário de Nossa Senhora do Perpetuo Socorro, Salgueiro, Pernambuco. Fonte: diocesedesalgueiro.com.br (data não informada).

1 A cidade de Salgueiro está localizada a 518 quilômetros de Recife, capital do estado, e possui clima semiárido. Segundo dados do censo realizado pelo IBGE em 2010, tinha uma população de 56.629 pessoas e Índice de Desenvolvimento Humano $\mathrm{Mu}$ nicipal (IDHM) de 0,669. A sua área territorial é de $1.686,814$ quilômetros quadrados (IBGE, 2020; PREFEITURA MUNICIPAL DE SALGUEIRO, 2020). da escadaria. A planta de situação, onde se encontram os elementos que compõem o conjunto - igreja, campanário e escadaria, foram desenhadas a partir de imagem obtida pelo Google Maps.

Espera-se que a discussão do artigo fomente o interesse entre historiadores, arquitetos e engenheiros sobre as autoconstruções, muito presentes na região, mas incipientemente documentadas e pesquisadas.

\section{Caracterização do objeto de estudo}

Localizado no bairro de Nossa Senhora do Perpétuo Socorro, o Santuário foi inaugurado em 1986 e sua construção era uma demanda da comunidade católica local, porém, a realidade daquela comunidade, em 1985, quando se deu início à construção, era a da ausência de assessoria de um profissional de arquitetura. Sendo assim, a forma do santuário foi idealizada pelo responsável pela paróquia, Padre Manoel Garcia. Consistia em uma planta octogonal composta por pilares dispostos radialmente, que pontuavam os vértices deste octógono, e que se uniam no topo da estrutura, através de uma pequena cúpula. Entre os pilares, os fechamentos eram formados por cantoneiras de ferro, formando espécies de grelhas, que foram executadas por um metalúrgico local, e vitrais que foram encomendados de fora da cidade. Com o passar do tempo, as grelhas foram cobertas por telhas metálicas, externamente, a fim de proteger o interior da igreja das intempéries (Figuras 2 e 3). A escadaria também fazia parte deste projeto original, mas não foi executada neste momento. 
Estudo da forma arquitetônica do Santuário Nossa Senhora do Perpétuo Socorro - Salgueiro/PE | 4
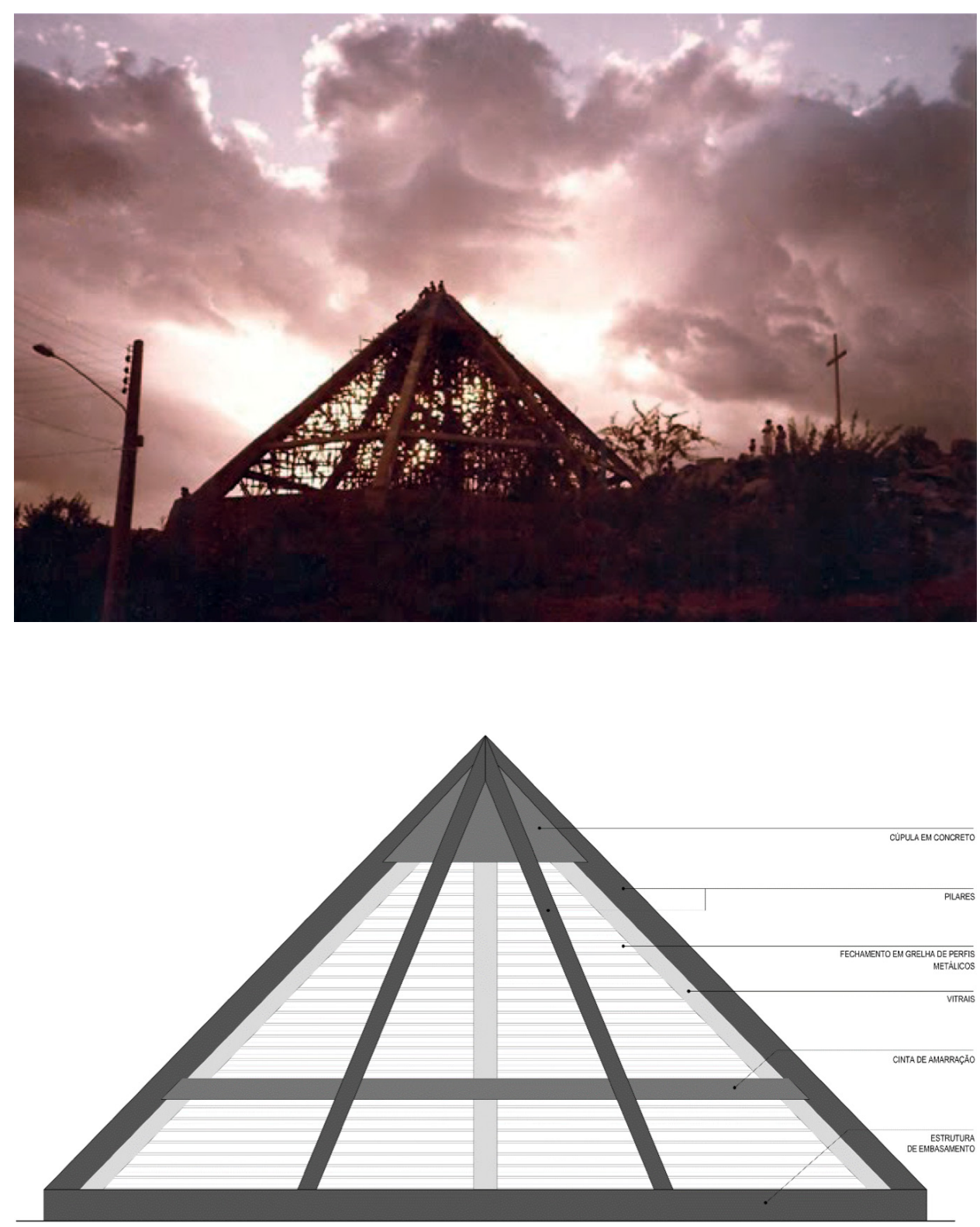

Figura 2: Santuário de Nossa Senhora do Perpetuo Socorro, em 1985, durante a construção. Fonte: mapio.net/microregiaodesalgueiro.

Figura 3: Reconstrução da fachada original do Santuário (segundo os relatos). Fonte: a equipe. 
2 Em depoimento público à equipe da pesquisa realizado no dia 12 de março de 2020, Marlene Lucas de Souza, filha de José de Oliveira Lucas, projetista e construtor do Santuário de Nossa Senhora do Perpétuo Socorro, falecido em 1985, e Francisco José de Souza, esposo de Marlene e carpinteiro que trabalhou na construção da igreja, relataram a história contada neste artigo, não registrada em nenhum documento conhecido na cidade de Salgueiro. No entanto, Marlene não sabe precisar as datas dos acontecimentos e relata que não possui nenhum dos projetos feitos pelo pai e nem o registro profissional do CREA aqui citado.

Figura 4: Detalhamento do afloramento de rocha fragmentada presente no subsolo do Catedral de Nossa Senhora do Perpetuo Socorro, Salgueiro, Pernambuco. Fonte: mapio.net (editada pela equipe).
A igreja - e sua estrutura - foi calculada e desenhada por José de Oliveira Lucas, conhecido na região, na época, como o "Engenheiro dos Pobres". Segundo relato de sua filha Marlene², ele não possuía formação acadêmica em Engenharia, mas prestou 32 testes junto ao Conselho Regional de Engenharia e Agronomia - CREA - em São Paulo, o que lhe garantiu um número de registro e o direito de assinar projetos, por possuir notório saber. Era, segundo ela, o único engenheiro da região, tendo projetado e construído outras obras públicas em Salgueiro e cidades vizinhas, como escolas municipais.

A estrutura de sustentação da igreja é constituída por pilares de seção trapezoidal, executados em concreto armado. Os mesmos nascem de vigas baldrames de seção retangular e com um metro de altura, também executadas em concreto armado, fixadas em uma rocha fragmentada que aflora na superfície do terreno. Na Figura 4 é possível observar alguns fragmentos da rocha no talude do terreno próximo ao campanário. Segundo o relato de Marlene e Francisco (2020), a obra contou com mais de dez trabalhadores, moradores da própria comunidade, que se revezavam nos diferentes afazeres, e que esta estrutura nunca precisou de reparos.

Sabe-se, ainda, que, no início da década de 1990, a igreja foi ampliada, quando adquiriu a forma atual. Para além da estrutura de pilares dispostos radialmente

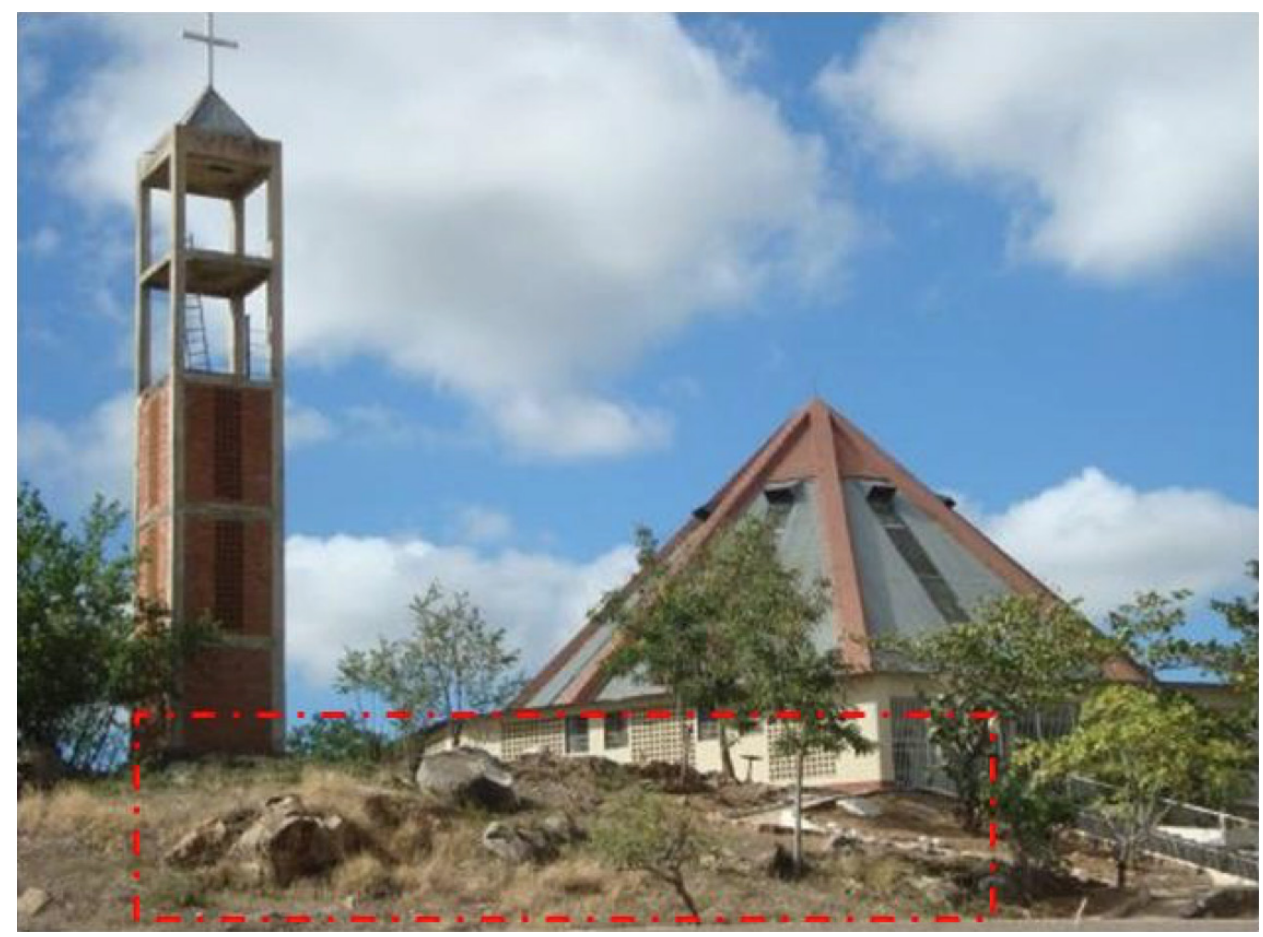



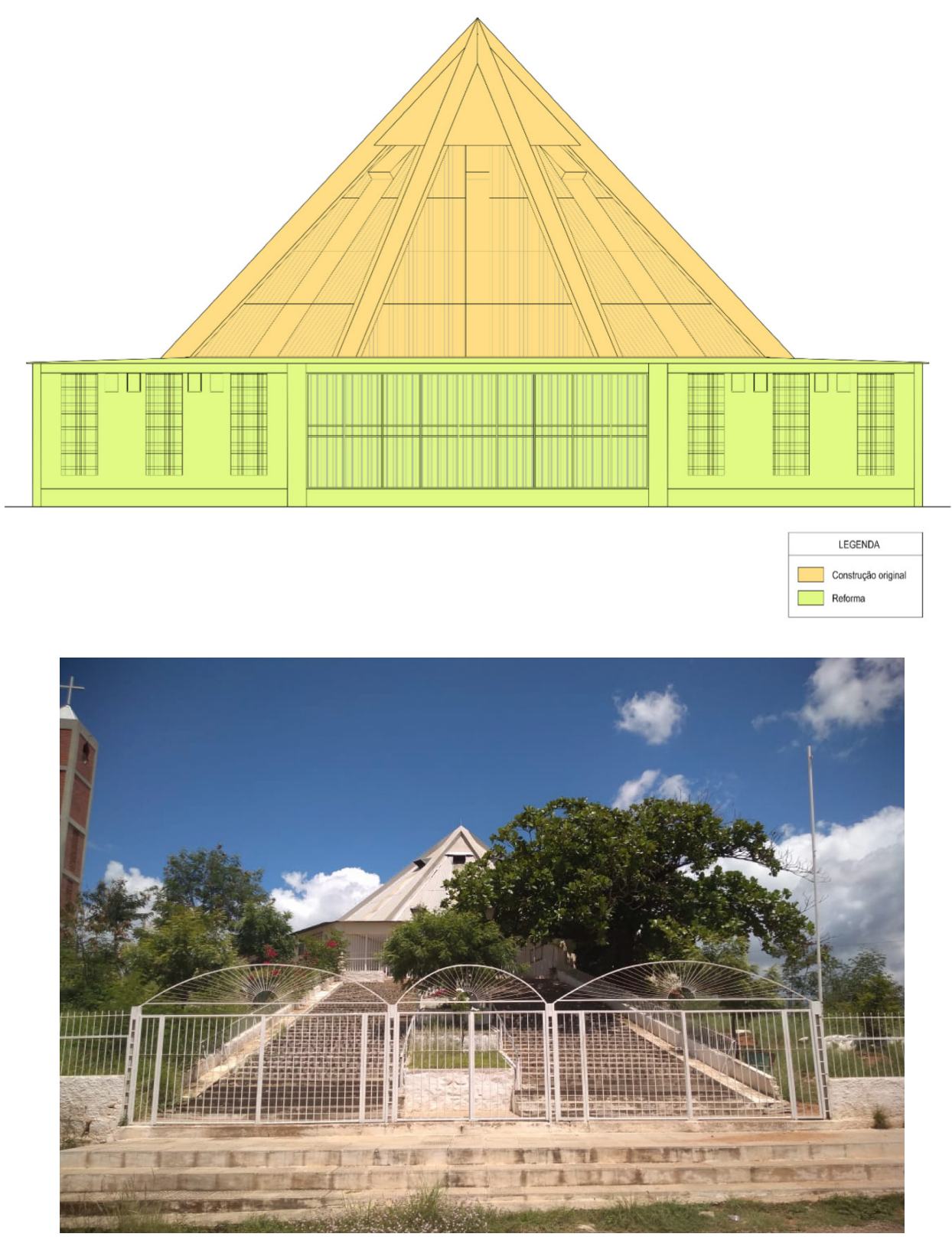

Figura 5: Relação entre a construção original e a reforma do Santuário. Fonte: a equipe.

Figura 6: Escadaria de acesso de pedestres ao Santuário de Nossa Senhora do Perpétuo Socorro. Fonte: a equipe.

${ }^{3} \mathrm{~A}$ equipe esteve em contato com o padre Remígio de Vettor, atual responsável pela paróquia, que informou que esta reforma contou com a assessoria de um engenheiro civil, mas o mesmo não soube informar o nome e nem possuía o projeto em questão. em uma planta octogonal, foi adicionado um volume em formato de prisma de base octogonal (Figura 05). Segundo o relato de Marlene (2020), as pessoas, ao se movimentar no interior do santuário, acabavam batendo com a cabeça nos pilares, e este foi o motivo da reforma. Não foi possível, no entanto, saber informações exatas de quando a mesma foi realizada e quem foi o responsável pela obra ${ }^{3}$.

Neste trabalho, o santuário de Nossa Senhora do Perpétuo Socorro foi considerado como uma autoconstrução, pois foi executado pela própria comunidade como resposta autônoma às suas necessidades utilizando-se de conhecimentos adquiridos previamente para a resolução de problemas de seu cotidiano, sem que estes indivíduos necessariamente possuam formação técnica (SÁ, 2009). 


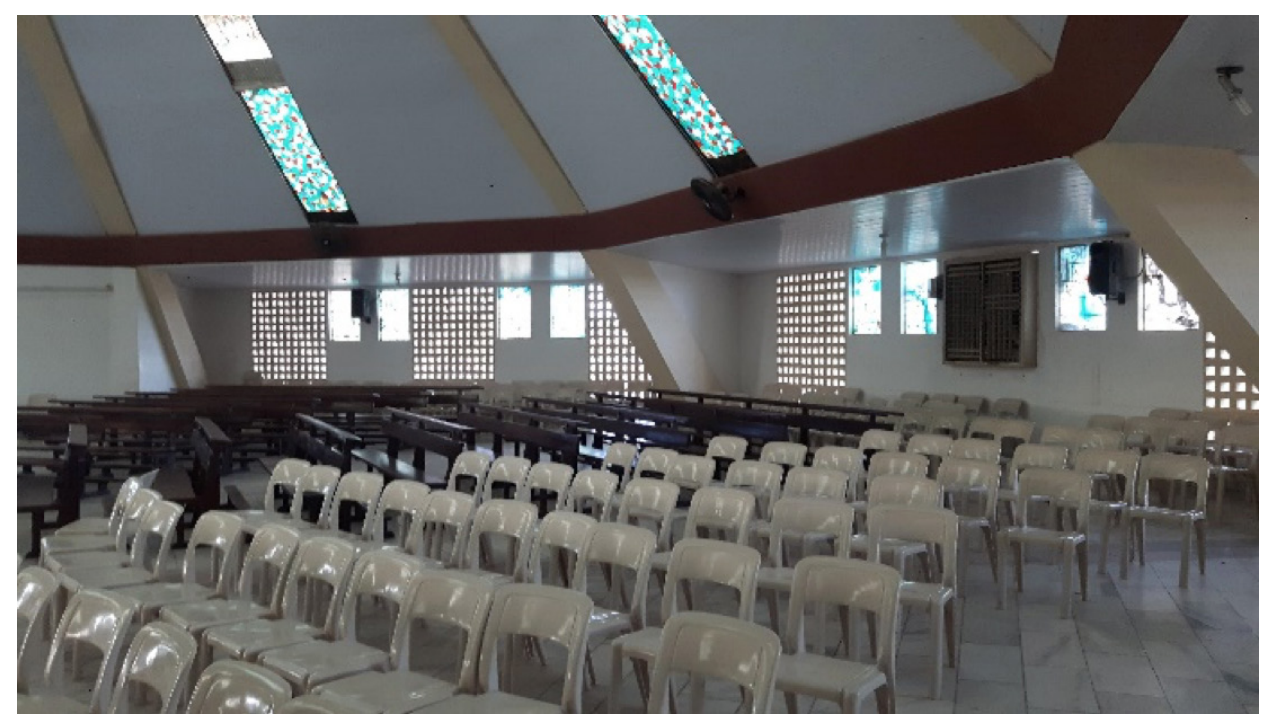

Figura 7 (topo): Área interna do Santuário de Nossa Senhora do Perpétuo Socorro, na qual se pode observar os pilares e partes das estruturas que compõem a construção original e a reforma. Fonte: a equipe.

Figura 8 (embaixo): Cúpula vista pelo interior do santuário. Também se observam os vitrais e as aberturas para ventilação natural. Fonte: a equipe.

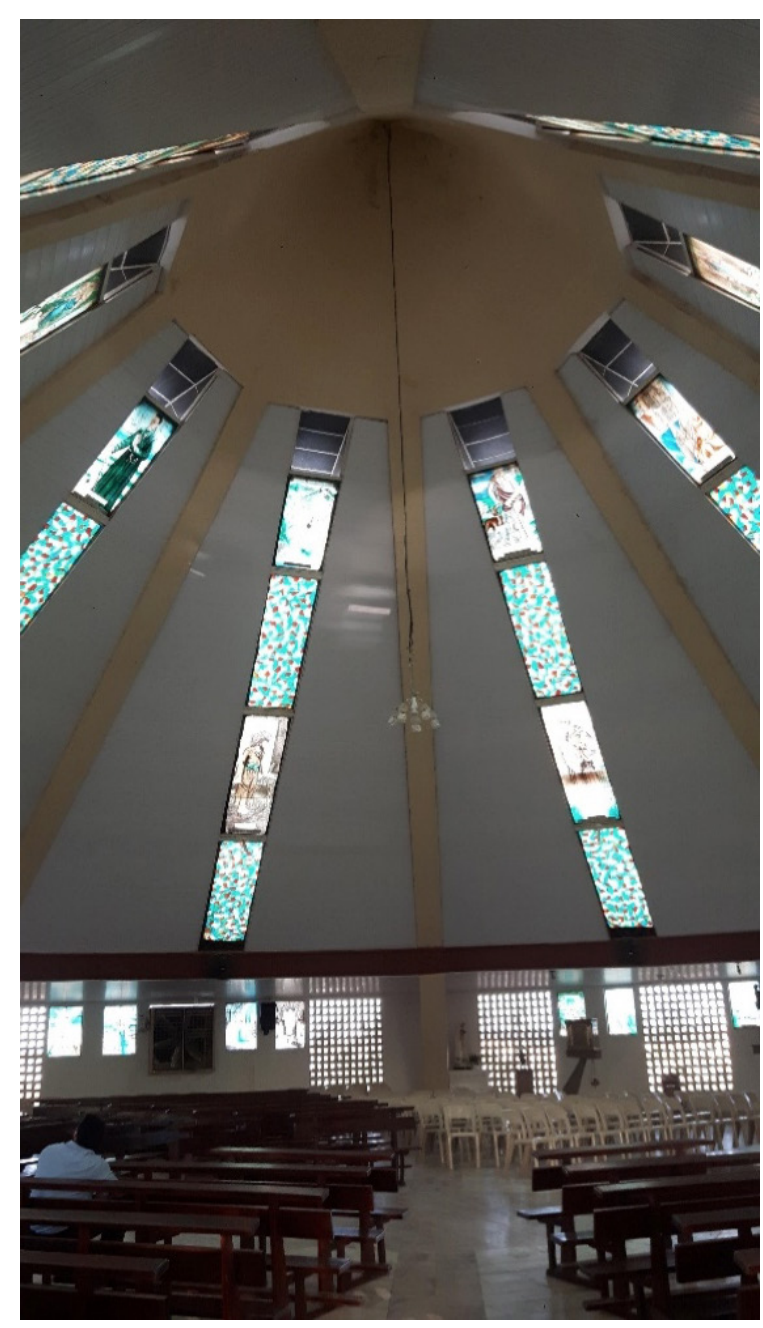




\section{Arquitetura de espaços sagrados modernos}

A arquitetura de espaços sagrados é permeada por seu encontro com a religiosidade e aspectos espirituais da existência humana, tendo suas raízes ancoradas em processos, crenças e paradoxos da própria sociedade, sendo os aspectos religiosos parte do arcabouço cultural que influencia diretamente a produção material humana. As obras arquitetônicas de caráter religioso passaram, ao longo desta história, por templos gregos e romanos, góticos e renascentistas, neoclássicos etc. (LIMA JUNIOR, 2016).

No século $X X$, ocorre uma importante ruptura no padrão tipológico arquitetônico sacro tradicional. A tipologia das plantas cruciformes passou a ser praticamente desconsiderada, pois, segundo Lima Junior (2016, p.17):

[...] na modernidade há uma crença de que a convergência do desenvolvimento econômico, do avanço da educação e da liberalização política iriam gerar sociedades cada vez mais secularizadas, onde todas as respostas da realidade da existência humana seriam reveladas unicamente pela ciência e pelo racionalismo vigente, imperando um materialismo cultural. O antigo relacionamento entre a Divindade, o Homem e o Mundo apareceria na modernidade como uma dualidade de apenas Homem e Mundo e as questões relativas à transcendência tornam-se mais enigmáticas.

O autor afirma que o princípio da imanência, inaugurado por Descartes e que determinaria os rumos da filosofia e da vida na modernidade, assim como do projeto moderno, foi considerado por muitos estudiosos "a via que levaria o pensamento até o grau de eliminação dos aspectos espirituais como realidade transcendente, junto do processo de afirmação da autonomia do homem" (LIMA JUNIOR, 2016, p. 17). Muitos arquitetos modernos enfrentaram o paradoxo entre este novo pensamento e entre a teoria secular dos espaços sagrados, quando precisaram traduzi-lo na materialidade.

Como se sabe, entre o final do século XIX e início do século XX, ocorrem importantes transformações nos campos das Artes Visuais e Arquitetura, momento em que se buscava novos meios de expressão que fossem baseados na tecnologia mecanicista e na geometrização das formas, o que eram reflexos do contexto que havia começado na Revolução Industrial. Na Arquitetura, isto foi sentido com a abolição dos ornamentos. Em 1908, o arquiteto austríaco Adolf Loos publicou o manifesto Ornament und Verbrechen (Ornamento e Crime), no qual considerava os adornos intoleráveis não só esteticamente, mas também eticamente. $\mathrm{O}$ argumento de Loos para a eliminação dos ornamentos era de que a execução destes significava perda de tempo e de materiais, além de implicar "uma forma punitiva de escravidão artesanal" (FRAMPTON, 2000, p.104). Para o arquiteto, os ornamentos arquitetônicos eram incompatíveis com as aspirações modernas, pois a sua realização dependia de várias formas de submissão, entre elas o fato de que eram executados por artesãos a partir dos desenhos de arquitetos e artistas, profissionais com mais prestígio social, distante da realidade das oficinas artesanais. Sendo assim, a criação de um estilo genuinamente moderno dependia da emancipação desses trabalhadores (PAIM, 2000). 
No que tange às construções de templos sacros, esta tendência também se repetiu. Externamente, houve a simplificação das formas e, no interior das edificações, foi percebida a ausência de ornamentos que retiraram do altar a posição de protagonismo. Esta simplicidade - que pode ser entendida como uma abstração das formas - pode ser vista em vários exemplares da arquitetura moderna sacra, em especial naquelas que possuem a tipologia de planta central, já citados anteriormente, o que confere a estes espaços um caráter comunitário. De acordo com Müller (2006), este foi um aspecto fundamental à arquitetura da reforma eclesiástica moderna: o caráter que deveriam assumir os espaços sagrados, nos quais a conformação central da planta resulta em um menor protagonismo do altar. Nesta nova configuração, as pessoas se reuniriam em volta do mesmo, conferindo uma nova função a estes espaços: promover o senso comunitário. Este é um importante contraponto à conformação tradicional das plantas cruciformes dos espaços sagrados católicos, as quais possuem a nave, transepto e abside bem definidos.

Sobre a arquitetura moderna brasileira, Arruda (2004) afirma que houve um movimento liderado por Lúcio Costa, a partir da década de 1930 até a construção de Brasília, na década de 1950, que é conhecido pela historiografia brasileira como Escola Carioca. Este grupo de arquitetos estava interessado na renovação da técnica e expressão arquitetônica que vinha ocorrendo desde o início do século, especialmente após a produção de Le Corbusier. Ainda segundo Arruda (2004), a Escola Carioca, mais do que um movimento de arquitetura moderna, transforma-o em um estilo brasileiro, a partir da adaptação do modernismo às condições climáticas locais:

A arquitetura se espalha pelos quatro cantos do Brasil, produzindo arquitetura moderna, pública ou privada, mas com certos cuidados com relação ao sítio e as transformações em função das características do lugar. O caráter dessa arquitetura se deu através da reunião dos elementos de arquitetura e de composição identificados nos seus mais importantes projetos, como os brises-soleil, o elemento vazado, os pilares de seção circular, além dos elementos corbusianos de composição cúbica e prismática. (ARRUDA, 2004)

O uso de elementos arquitetônicos tais quais os brise-soleil e os elementos vazados de concreto - conhecidos como cobogós (ou combogós) - foram amplamente usados na adaptação às condições naturais de iluminação e ventilação. No nordeste, estes elementos surgem como soluções apontadas por Holanda (1976), no clássico "Roteiro para Construir no Nordeste":

Combinemos as paredes compactas com os panos vazados, para que filtrem a luz e deixem a brisa penetrar. Tiremos partido das imensas possibilidades construtivas e plásticas do elemento vazado de parede - o combogó - que pode assumir uma ampla gama de configurações entre filigrana e marcado jogo de relevos. (HOLANDA, 1976, p. 19)

Segundo Arruda (2004), estes elementos da arquitetura moderna, além de terem se difundido pelo meio profissional da Arquitetura, possibilitou a construção de um repertório que também podem ter se tornado referência para as construções populares, mesmo aquelas distantes do eixo cultural do Rio de Janeiro e São Paulo. 


\section{Análise da forma arquitetônica do Santuário Nossa Senhora do Perpétuo Socorro}

A seguir serão apresentados os resultados técnico-observacionais da discussão sobre a forma arquitetônica do Santuário de Nossa Senhora do Perpétuo Socorro e algumas considerações acerca do alcance da arquitetura modernista sobre o repertório visual e a cultura material popular.

A análise da forma arquitetônica da edificação, em sua forma atual, revela ser composta por dois volumes que se unem: base e coberta. A coberta, que se constitui de uma pirâmide de base octogonal, representa uma seção da forma inicial da igreja. Este volume é formado pela estrutura principal de sustentação da edificação, que é composta por oito elementos estruturais de concreto armado que se repetem em uma conformação radial, formando uma pirâmide. No topo, o coroamento é composto por um fechamento em concreto, como uma pequena cúpula, que une os oito elementos de sustentação. Intercalados a estes elementos (pilares), encontram-se aberturas para iluminação (vitrais com esquadria metálica) e ventilação naturais (aberturas em estrutura metálica e fechamento em policarbonato opaco). O fechamento é composto por telhas metálicas, externamente, e por forro de PVC, internamente (Figuras 9 e 10).

A base, um volume em formato de prisma de base que também possui oito lados, configura a reforma realizada na década de 1990. A estrutura de sustentação da edificação original pontua os vértices desta base octogonal. Os fechamentos são compostos por alvenaria, que também possuem elementos para iluminação e ventilação naturais - vitrais com esquadria metálica e elementos vazados de concreto (cobogó). A cobertura é composta pelo mesmo tipo de telha metálica do fechamento da parte superior (Figuras 11 e 12).

Ainda compõem o conjunto da edificação: a escadaria, que possui um canteiro central, e o campanário, uma torre de base quadrada em estrutura de concreto e fechamento em alvenaria de tijolo cerâmico aparente. Estes elementos não entraram na análise da forma e nem no levantamento, pois: 1) seria necessário um levantamento topográfico da escadaria; 2) a equipe não possuiu meios para levantar a altura do campanário, nem mesmo por aproximação, como foi feito com a igreja.

A planta central da igreja e a estrutura em concreto armado composta por elementos dispostos radialmente, presentes no Santuário de Nossa Senhora do Perpétuo Socorro (Figura 12), levam à compreensão de que este pode ser caracterizado como um exemplar arquitetônico modernista. Sobretudo quando se compara a forma do santuário estudado neste trabalho com outros importantes templos sacros brasileiros idealizados por arquitetos e tidos como modernistas, como a Catedral Metropolitana de Brasília, projetada pelo arquiteto Oscar Niemeyer na década de 1950 e inaugurada em 1970 (Figura 14), a Catedral de Nossa Senhora das Dores, projetada pelo arquiteto José Luiz Mota Menezes e inaugurada em 1973, localizada na cidade de Caruaru (Figura 15), e a Catedral Metropolitana do Rio de Janeiro, projetada pelo arquiteto Edgar Fonseca e inaugurada em 1976 (Figura 16).

Além disto, percebe-se o aproveitamento das condições locais, como ventilação e iluminação naturais, a partir da utilização de elementos vazados - cobogós, um traço marcante da arquitetura moderna brasileira. Ainda que não tenha sido idealizado por um profissional arquiteto ou engenheiro, pode-se concluir que a arquitetura moderna brasileira constitui um estilo que criou um repertório visual que teve um grande alcance, mesmo fora do meio acadêmico ou profissional. 


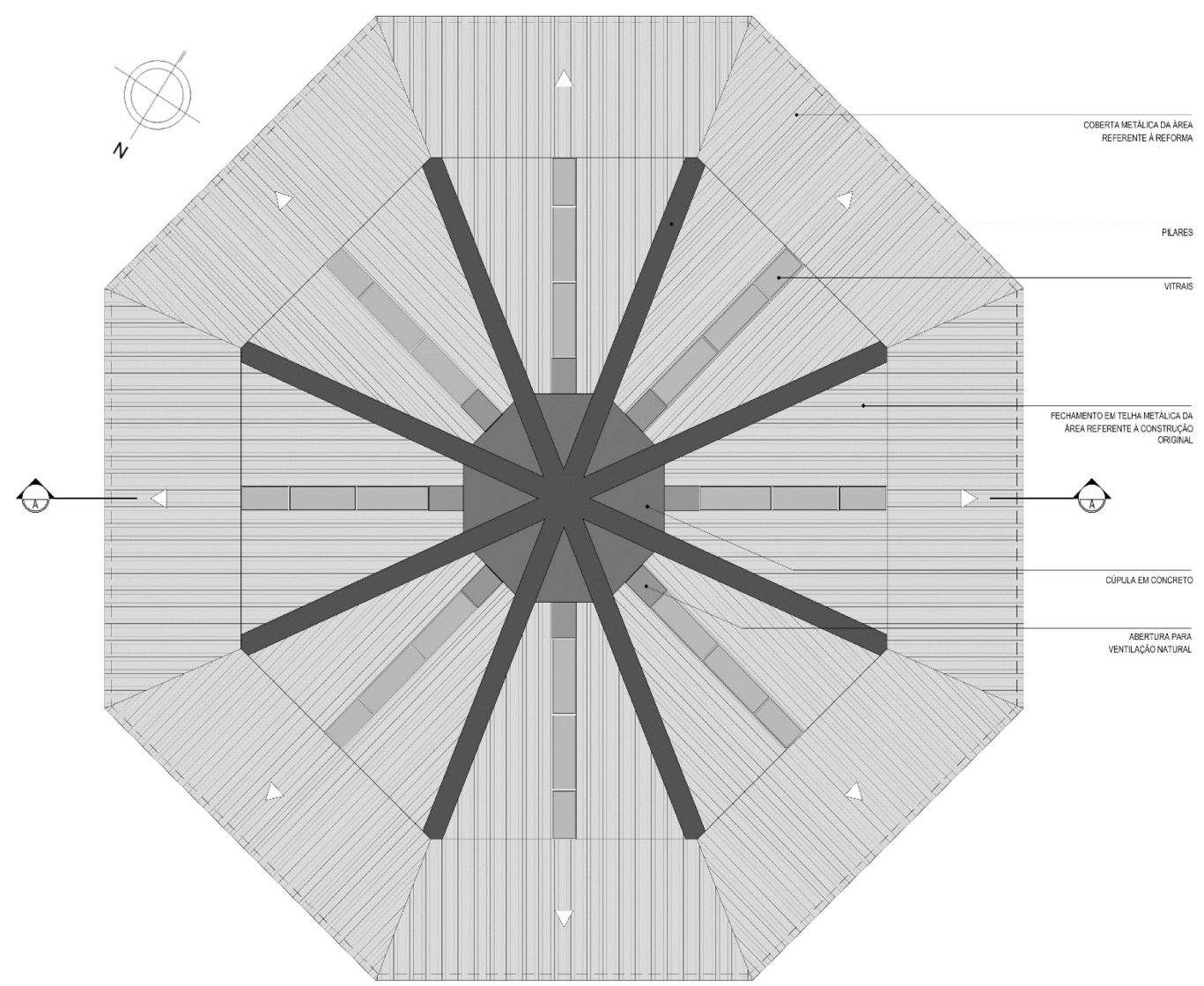

Figura 9 (topo): Planta de co-

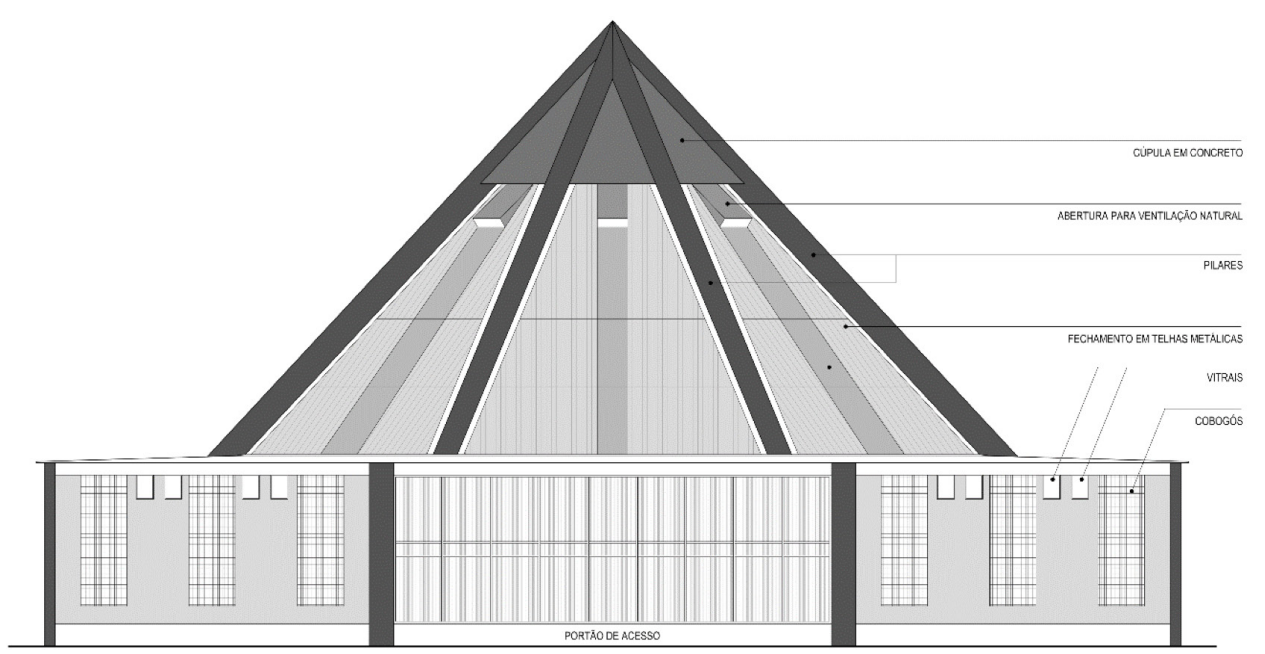
berta do Santuário de Nossa Senhora do Perpétuo Socorro. Fonte: a equipe.

Figura 10 (embaixo): Fachada atual do Santuário de Nossa Senhora do Perpétuo Socorro. Fonte: a equipe. 

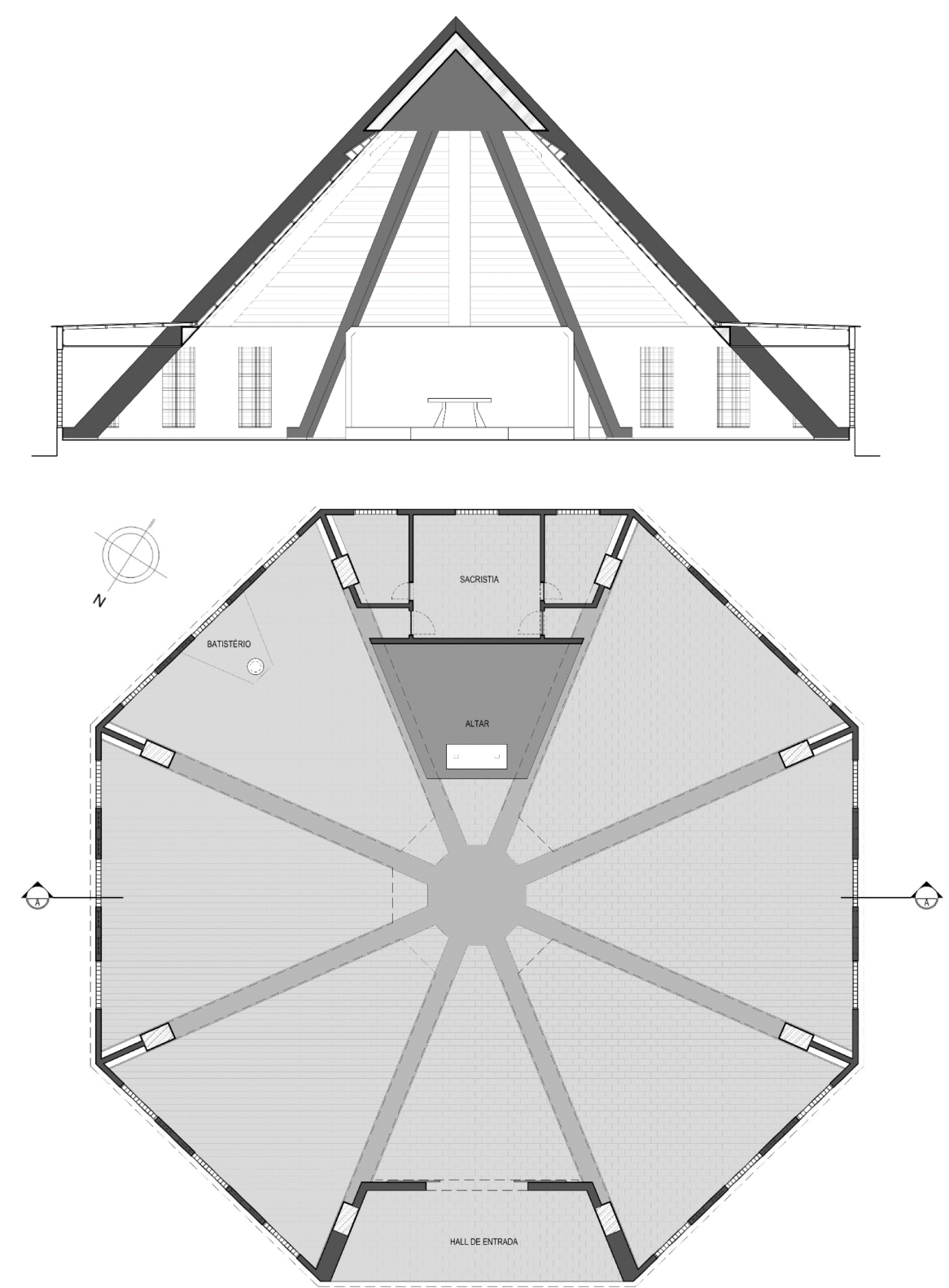

Figura 11 (topo): Corte AA. Fonte: a equipe.

Figura 12 (centro): Planta Baixa do Santuário de Nossa Senhora do Perpétuo Socorro. Fonte: a equipe.

Figura 13 (embaixo): Planta de situação. Fonte: a equipe.

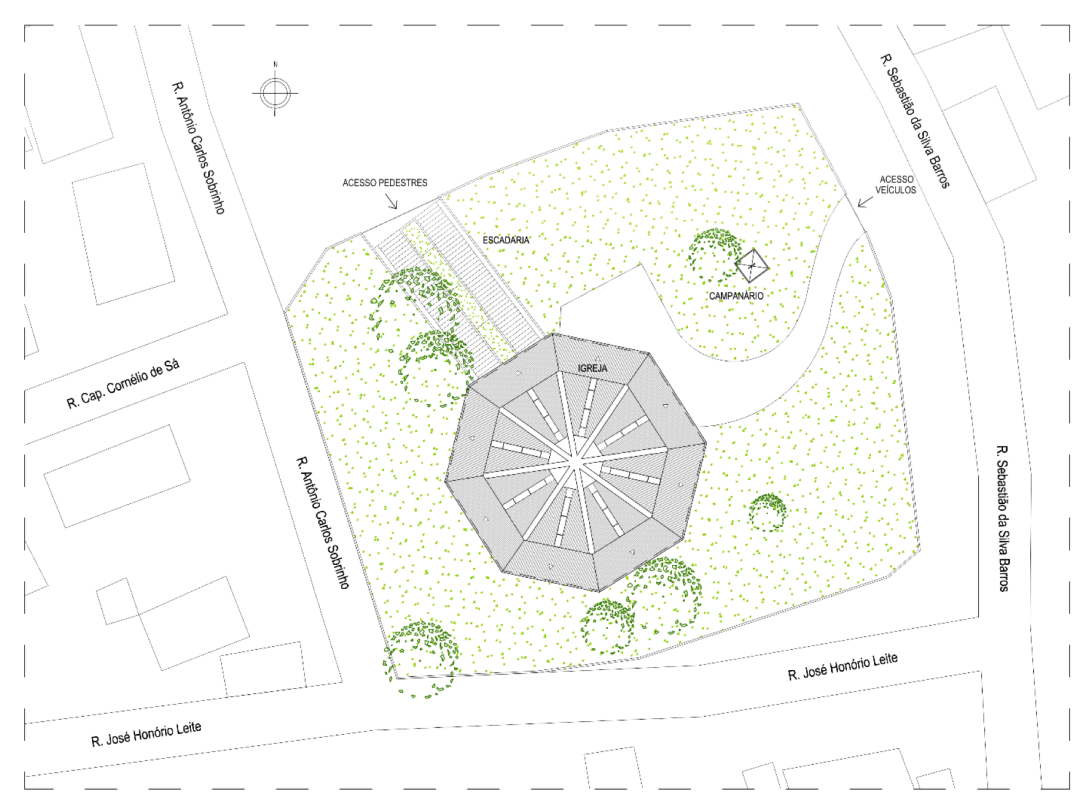



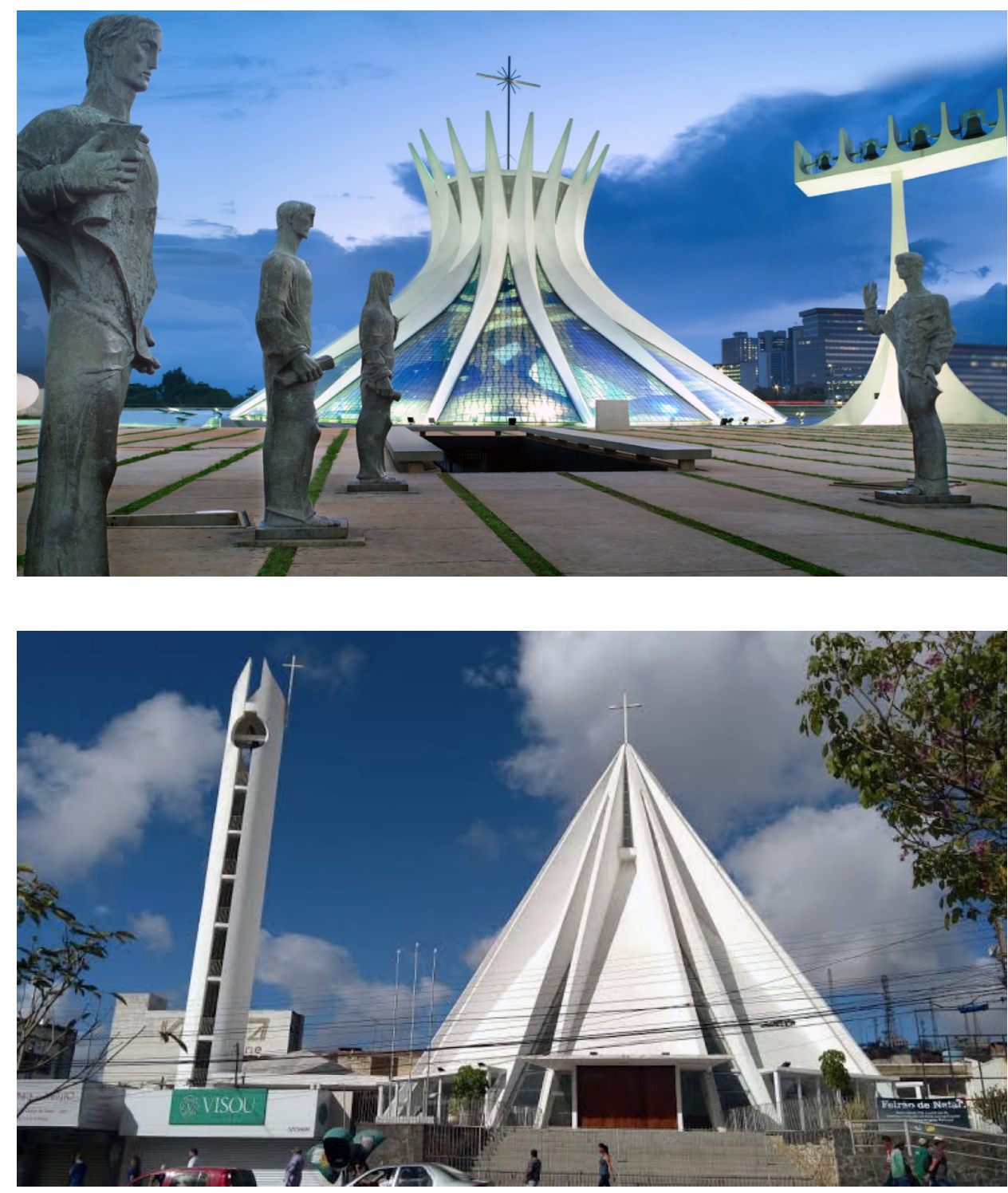

Figura 14: Catedral Metropolitana de Brasília, Distrito Federal. Fonte: culturagenial.com/ catedral-de-brasilia.

Figura 15: Catedral de Nossa Senhora das Dores, Caruaru, Pernambuco. Fonte: <https:// diocesedecaruaru.org/>.

Figura 16: Catedral Metropolitana do Rio de Janeiro, Rio de Janeiro. Fonte: wikipedia.org.

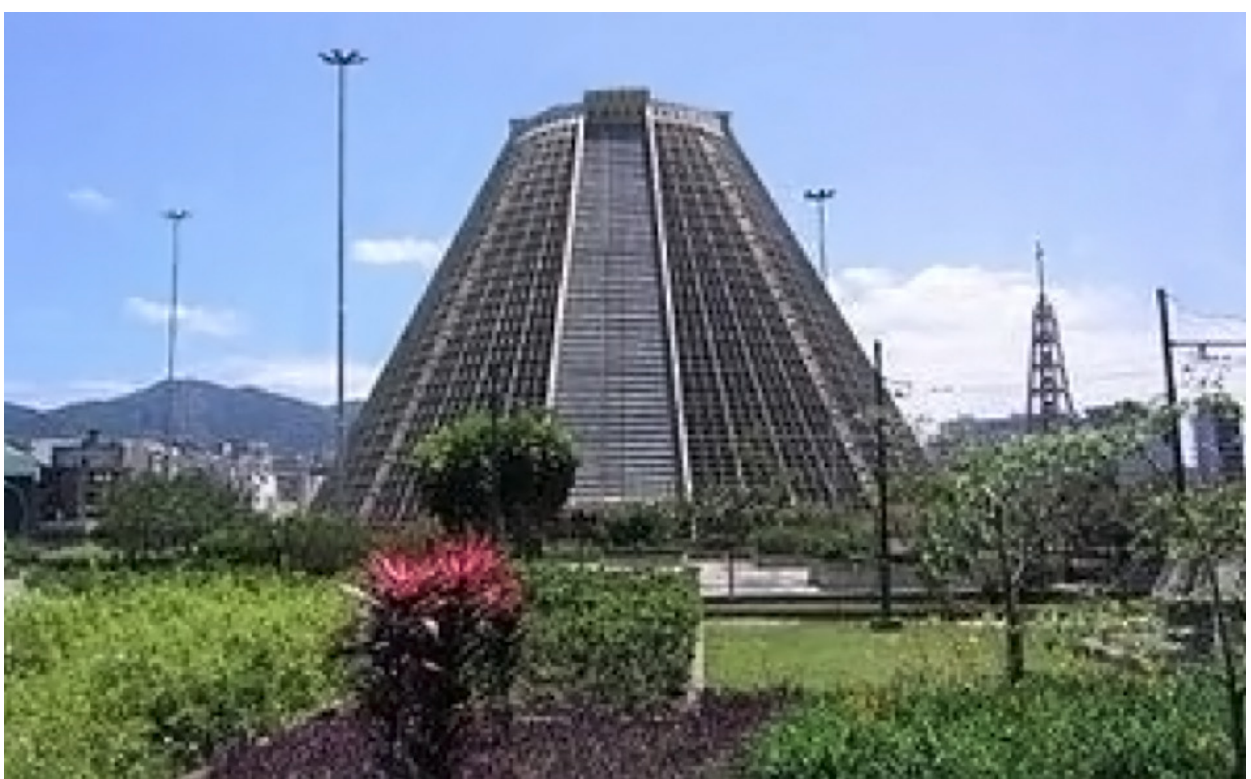




\section{Considerações finais}

Com o objetivo de analisar a forma arquitetônica do Santuário de Nossa Senhora do Perpétuo Socorro, e verificar a edificação enquanto exemplar de arquitetura de estilo modernista, o estudo explorou a apropriação popular de elementos básicos da arquitetura moderna em uma construção religiosa no sertão de Pernambuco.

O estudo da bibliografia relativa ao projeto, os levantamentos fotográfico, métrico e documental foram realizados dentro dos prazos estabelecidos, bem como o desenho técnico arquitetônico. Porém, a equipe não dispôs de suporte técnico para a correta realização do levantamento topográfico do local, o que inviabilizou a realização do levantamento e locação do campanário e da escadaria, durante o decorrer da pesquisa.

A análise da forma arquitetônica permitiu avaliar o grau de proximidade entre a arquitetura do Santuário e outras edificações sacras modernistas. Através de análise comparativa, a forma desta edificação foi relacionada a exemplares de templos sagrados modernos que também possuem planta central e estrutura radial em concreto armado, além da sobriedade com relação ao emprego de ornamentos. Desta forma, corroborando com os achados de outros estudos, a pesquisa identificou que a influência da arquitetura moderna na produção de construção por construtores populares de "notório saber", a ponto de influenciar a forma de planejar as edificações, mesmo fora do meio profissional da educação formal da Arquitetura e da Engenharia. Dessa forma, a questão que surgiu no grupo de estudos com a equipe da pesquisa foi reconstruída: Será que o fato de não ter sido projetada por um arquiteto ou engenheiro desqualifica a obra enquanto exemplo de arquitetura moderna? Os debates levaram a conclusão que não. Embora as lacunas no planejamento e na racionalização presentes no Santuário, elementos inerentes ao próprio pensamento e projeto moderno de controle do mundo por meio da manipulação da razão e do saber científico, não tenham sido ignorados pela equipe do grupo de pesquisa.

Pode-se dizer, portanto, que o Santuário de Nossa Senhora do Perpetuo Socorro, situado em Salgueiro, mesmo não tendo sido idealizado por um profissional com formação em Arquitetura, ou seja, fruto de uma arquitetura sem arquitetos, representa um exemplar de arquitetura moderna, apresentar uma forma muito próxima àquela de santuários projetados por arquitetos e que são classificados como tal.

\section{Referências bibliográficas}

ARAKAKI, Suyenne Riether; AZAMBUJA, Eduardo Bicudo de Castro; SÁNCHEZ, José Manoel Morales. Forma Arquitetônica e Função Estrutural da Igreja Nossa Senhora de Fátima em Brasília. Paranoá: cadernos de arquitetura e urbanismo, [s.I.], n. 15, p.63-69, 31 dez. 2015. Programa de Pós-graduação em Arquitetura e Urbanismo - Univ. de Brasília. http://dx.doi. org/10.18830/issn.1679-0944.n15.2015.05. Disponível em: <http://periodicos.unb.br/ index.php/paranoa/article/view/19745>. Acesso em: 08 out. 2018.

ARRUDA, Ângelo Marcos. A popularização dos elementos da casa moderna em Campo Grande, Mato Grosso do Sul. Arquitextos, São Paulo, n. 047, abr. 2004. Disponível em: <https:// www.vitruvius.com.br/revistas/read/arquitextos/04.047/596>. Acesso em: 30 out. 2019.

BENEVOLO, Leonardo. História da arquitetura moderna. 3.ed. São Paulo: Perspectiva, 2004. $813 \mathrm{p.}$ 
DIOCESE DE SALGUEIRO. Disponível em: <http://diocesedesalgueiro.org.br/local/perpetuo-socorro-salgueiro>. Acesso em: 08 out. 2018.

EMPETUR. Inventário Turístico de Pernambuco - INVTUR - PE. Disponível em: <http://inventariope.blogspot.com/2018/03/>. Acesso em: 08 out. 2018.

FRAMPTON, Kenneth. História crítica da arquitetura moderna. São Paulo: Martins Fontes, 2000.

HOLANDA, Armando de. Roteiro para Construir no Nordeste: Arquitetura como lugar ameno nos trópicos ensolarados. Recife: Editora da Universidade Federal de Pernambuco, 1976. Disponível em: <https://www.academia.edu/15452693/Roteiro_para_construir_no_nordeste>. Acesso em: 02 nov. 2019

IBGE. Conheça Cidades e Estados do Brasil. Disponível em: <https://cidades.ibge.gov.br/brasil/ pe/salgueiro/panorama>. Acesso em: 23 mar. 2020.

LIMA JUNIOR, Márcio Antonio de. O Traço Moderno na Arquitetura Religiosa Paulista. 2016. 368 f. Dissertação (Mestrado) - Curso de Arquitetura e Urbanismo, Universidade de São Paulo, São Paulo, 2016. Disponível em: <file:///C:/Users/Isabel/Downloads/marcioantonio. pdf>. Acesso em: 30 out. 2018.

MONTANER, Josep Maria. Arquitetura e Crítica. Barcelona: Gustavo Gili, 2015. 160 p.

Depois do movimento moderno: arquitetura da segunda metade do século XX. Barcelona: Gustavo Gili, 2001. 271 p.

MÜLLER, Fábio. O templo cristão na modernidade: permanências simbólicas \& conquistas figurativas. 2006. 374 f. Dissertação (Mestrado) - Curso de Arquitetura, Universidade Federal do Rio Grande do Sul, Porto Alegre, 2006. Disponível em: <https://lume.ufrgs.br/ handle/10183/5745>. Acesso em: 09 nov. 2018.

PAIM, Gilberto. A beleza sob suspeita: O ornamento em Ruskin, Lloyd Wright, Loos, Le Corbusier e outros. Rio de Janeiro: Jorge Zahar, 2000.

PREFEITURA MUNICIPAL DE SALGUEIRO. Salgueiro em Números. Disponível em: <http://www. salgueiro.pe.gov.br/munic_numeros.htm>. Acesso em: 23 mar. 2020.

SÁ, Werther Lima Ferraz de. Autoconstrução na cidade informal: Relações com a política habitacional e formas de financiamento. 2009. 176 f. Dissertação (Mestrado) - Programa de Pós-graduação em Desenvolvimento Urbano, Departamento de Arquitetura e Urbanismo, Universidade Federal de Pernambuco, Recife, 2009. Disponível em: <https://repositorio. ufpe.br/bitstream/123456789/2879/1/arquivo154_1.pdf>. Acesso em: 02 nov. 2019.

SCOTTÁ, Luciane. Arquitetura religiosa de Oscar Niemeyer em Brasília. 2010. 319 f. Dissertação (Mestrado) - Curso de Arquitetura e Urbanismo, Universidade de Brasília, Brasília, 2010. Disponível em: <http://repositorio.unb.br/handle/10482/7361?mode=full>. Acesso em: 08 out. 2018

TAFURI, Manfredo; DAL CO, Francesco. Architettura Contemporanea. Milão: Electa, 2009. 428 p. (Storia universale dell'architettura). 